\title{
Imigrantes italianos no interior de São Paulo (1895-1925): uma história de socialização e adaptação em novos padrões culturais e identitários do Brasil do início do século $\mathrm{XX}^{1}$
}

\author{
Inmigrantes italianos en el interior de São Paulo (1895-1925): una \\ historia de socialización y adaptación a los nuevos patrones culturales e \\ identitarios en Brasil a principios del siglo XX
}

\author{
Italian immigrants in the interior of São Paulo (1895-1925): a history of \\ socialization and adaptation to new cultural and identity patterns in Brazil \\ at the beginning of the 20th century
}

Fernando Tadeu Germinatti ${ }^{2}$

\begin{abstract}
Resumo
O presente trabalho se propõe a refletir de forma interdisciplinar a respeito da vinda dos imigrantes italianos ao interior de São Paulo, e nesse propósito, pensar como ajudaram a construir uma nova raça e identidade nacional brasileira. Este texto analisa através de elementos históricos e tenciona compreender os elementos estruturais sócio-políticos que condicionaram e incentivaram os processos imigratórios. Assim sendo, ao considerar os imigrantes como atores sociais que estabelecem práticas culturais em seu espaço praticado e seu envolvimento com outros espaços culturais, parte-se a pensar sobre a profusão de configurações identitárias que se moldam ao tempo e espaço praticado. A metodologia utilizada aproveitou obras e conceitos das diversas áreas do saber, visando um englobamento mais proveitoso para a pesquisa. Assim, tem-se por objetivo trazer a questão imigratória como enfoque central da discussão envolvendo, articulando então a massa imigratória do início do século XX com a configuração e condição econômica, social e cultural.
\end{abstract}

Palavras-Chave: Identidade; socialização; imigração; Cultura.

\section{Resumen}

El presente trabajo propone reflexionar de manera interdisciplinaria sobre la llegada de inmigrantes italianos al interior de São Paulo, y con ese propósito, pensar cómo ayudaron a construir una nueva raza y una identidad nacional brasileña. Este texto analiza elementos históricos y pretende comprender los elementos sociopolíticos estructurales que condicionaron y alentaron los procesos de inmigración. Por lo tanto, cuando se considera a los inmigrantes como actores sociales que establecen prácticas culturales en su espacio practicado y su participación en otros espacios culturales, uno comienza a pensar en la profusión de configuraciones de identidad moldeadas por el tiempo y el espacio practicado. La metodología utilizada aprovechó los trabajos y conceptos de diferentes áreas del conocimiento, con el objetivo de una inclusión más fructífera para la investigación. Por lo tanto, el objetivo es llevar el tema de la inmigración como un foco central de la discusión que involucra, y luego articular la masa de inmigración de principios del siglo XX con la configuración y condición económica, social y cultural.

Palabras claves: la identidad; socialización; la inmigración; cultura.

\footnotetext{
${ }^{1}$ Artigo apresentado no Simpósio Temático: 01: Jovens Pesquisadores - Temática Livre, durante o I Congresso Internacional Online de Estudos sobre Culturas - Centro Latino-Americano de Estudos em Cultura (CLAEC), Brasil, 2019.

${ }^{2}$ Mestrando em história; Universidade Estadual do Centro-Oeste - UNICENTRO; Guarapuava, Paraná; Brasil; Germinattifer@outlook.com
} 


\begin{abstract}
The present work proposes to reflect in an interdisciplinary way about the arrival of Italian immigrants to the interior of São Paulo, and in that purpose, to think about how they helped to build a new race and Brazilian national identity. This text analyzes through historical elements and intends to understand the structural sociopolitical elements that conditioned and encouraged the immigration processes. Therefore, when considering immigrants as social actors who establish cultural practices in their practiced space and their involvement with other cultural spaces, one starts to think about the profusion of identity configurations that are shaped by the time and space practiced. The methodology used took advantage of works and concepts from different areas of knowledge, aiming at a more fruitful inclusion for research. Thus, the objective is to bring the immigration issue as a central focus of the discussion involving, then articulating the immigration mass of the beginning of the 20th century with the economic, social and cultural configuration and condition.
\end{abstract}

Key words: Identity; socialization; immigration; Culture.

\title{
1. Introdução
}

A vinda dos imigrantes italianos ao Brasil configura-se como um dos maiores fluxos imigratórios do mundo. Em vista disso, a possibilidade de trabalhar a presente temática faz-se pela necessidade em analisar o movimento imigratório de indivíduos italianos que se destinaram ao estado de São Paulo, especialmente durante 1895 e 1925, associando o movimento da imigração como instrumento de melhoria da cultura e da raça brasileira. Para tanto, visando obter um percurso minimamente satisfatório para o melhor desenvolver teórico-metodológico da pesquisa, o presente artigo toma um viés interdisciplinar, emprestando contribuições e conceitos da antropologia, história, economia, literatura e de Ciência Política.

Em linhas gerais, partindo do pressuposto argumentativo de trânsitos populacionais humanos e a necessidade do indivíduo em deixar seu espaço de origem, distintas culturas em trânsito pelo espaço urbano geraram conflitos e assimilações, assim sendo, o trabalho que se segue, pretende ter em mente que os processos imigratórios que tomaram conta dos discursos políticos no pós abolição como forma de "branquear" a população, representavam os anseios políticos que calcavam-se nos discursos eugenistas para atrair imigrantes europeus brancos, tidos com boas marcas culturais e raciais.

Insta salientar que, influenciadas por discursos e práticas, as imigrações de sujeitos europeus foram levadas ao patamar de evolução, em prisma cultural, social e humano. Se, segundo o sociólogo estadunidense Douglas Massey (1990), as migrações internacionais surgem como questão política a partir das grandes navegações do século XVI, a questão das migrações involuntárias vai ocupar a agenda internacional a partir da pós- guerra, é de se 
supor que os encontros entre estrangeiros eram inevitáveis, e com eles as trocas de informações, e principalmente seus jeitos, gostos, linguagens.

Ora, nesse sentido, conforme esse conjunto de elementos se fazia presente nas transições internacionais, em tempos coloniais do descobrimento do "novo mundo", principalmente ao que toca no contanto e enfrentamento de culturas díspares. Posteriormente, entre os séculos XVII e XVIII há uma alteração das formas de imigração ao Brasil, questão incrementada pelo avanço e intensificação do negro escravizado, é importante deter-se para a questão de que o desenrolar do século XVII ao XVIII inclina-se para o fator econômico no arrojamento das atividades cafeeiras que se espalhavam pelos recantos do Brasil.

Cumpridas as colocações iniciais, no mais, trata-se de infundir e compreender um poderoso lócus profícuo de reflexão ao que tange os processos decisórios da vinda dos imigrantes italianos ao Estado de São Paulo do fim do século XIX ao século XX, paradoxalmente, as relações estabelecidas com o advento imigratório declaram um movimento de fluxo contínuo e trocas identitárias, e assim, na esteira deste debate, aponta-se condições imigratórias especificas que dessem condição e margem de pensar um país civilizatório e industrializado, e como não poderia deixar de ser, com uma vertente cultural Europeia.

Em vista disso, diante do quadro que se estabelece, não seria exagero pensar, então, que os indivíduos foram "distribuídos" pelas cidades de acordo com suas condições econômicas, raças, costumes e práticas sociais aderindo, assim, a novos hábitos e costumes, outrossim, ao evocar o ingresso dos imigrantes italianos em um contexto sociocultural dispare e plural, é nesse caminhar que o cientista social Ruben George Oliven entende que cidade constitui-se em um espaço de múltipla convivência de/para diversos grupos com experiências e vivência em parte comum, em parte diferente (OLIVEN, 1996)

Seguindo a perspectiva de Oliven(1996), encontram-se múltiplas possibilidades de análise ao que tange o encontro e entrosamento de identidades culturais, mediado entretanto, por um discurso político voltado ao incremento do indivíduo europeu como forma de civilizar o Brasil, país envolto às manifestações culturais indígenas e negras, o que para a elite aristocrática ex- escravocrata, significava o atraso do país frente ao novo mundo, que teria em suas bases de sustentação o apoio no capitalismo industrial, na ciência, na cultura do europeu. 
Outrossim, por esse viés de pensamento, ao voltar o debate para as influências e causas das imigrações europeias ao Brasil, suscita-se encontrar um discurso mantido e promovido pelas elites em atrair o italiano como forma de fortificar (e embelezar) a raça e cultura brasileira. Destarte, contempla-se um novo cenário em que a imigração renasce enquanto estratégia política, em que aqui, a veremos num prisma um tanto interdisciplinar, por sua ligação aos desejos de remodelação racial da nação e ao mesmo tempo braços para a lavoura cafeeira paulista.

\section{Desenvolvimento}

\subsection{Construção identitária do imigrante e a busca pela identidade nacional}

A priori, o historiador Jeffrey Lesser (2001) chamou de negociação de identidade, isto é, articulações entre os imigrantes na busca de uma posição mais privilegiada na hierarquia social a partir de investimentos simbólicos que diluam o caráter depreciativo de suas identidades, concedendo a estas, sentidos mais aceitos e valorizados. Portanto, partindo do pressuposto argumentativo de que as migrações ao longo da história humana se fazem presentes pelo fato da necessidade do ser em encontrar melhor local para sua vivência, uma vez que, sua deslocação do ambiente de origem é causada por conflitos, crises econômica, influências climáticas como secas, alagações, frio em excesso, perseguição por motivos religiosos e políticos etc.

Faz-se imperial investir as causas imigratórias de forma ampla e plural. Assim sendo, a análise que se inicia, privilegia as razões da imigração italiana ao Brasil, mais particularmente para São Paulo, do fim do século XIX ao início do século XX. Destarte, quando aplicada a discussão para o estado de São Paulo, o historiador Boris Fausto na obra Historiografia da Imigração para São Paulo(1991) vai ressaltar que:

\footnotetext{
Nas condições de São Paulo, se deu um profundo interrelacionamento entre a sociedade nacional e as várias etnias e destas entre si. A tal ponto, que é possível pensar em uma "nova sociedade paulista", constituída por nacionais, imigrantes e seus descendentes, com traços próprios e diferenciados relativamente a outras regiões do país. É possível ainda pensar em uma "ideologia paulista" do trabalho, constituída a partir do esforço dos imigrantes e das representações mentais a eles associadas (FAUSTO, 1991, p. 38).
}

Pelo excerto exposto, é nítida a transição pelo espaço da cidade paulistana de imigrantes de origens distintas, com particularidades, costumes, modos e idiomas diversos. No presente artigo, em particular, nos deteremos em analisar as imigrações de europeus 
ocorridas na modernidade, respeitando o recorte temporal do fim do século XIX ao início do século XX. Parte-se, neste artigo, da intenção em olhar os discursos em atrair um tipo de imigrante que coincidiria com um indivíduo portador de "boas características" físicas, sociais e culturais. De tal forma que, a partir do século XIX, ancoram-se as características biológicas como definidora das relações sociais.

No bojo deste debate, ao mesmo tempo que havia uma questão econômica em torno do debate da substituição da mão de obra, sinais políticos chamavam a atenção para o fator de aplicar no Brasil uma higienização da raça, de modo, que os imigrantes seriam peça chave para se implantar discursos de limpeza das impurezas deixadas pela soberania da raça negra, constituindo uma questão econômica e de raça. Ou seja, utilizando-se do artifício discursivo da substituição de mão de obra escrava por uma mão de obra branca e europeia e assim mais avançada mental e civilizadamente, optou-se pelo imigrante em detrimento do negro. A partir deste refluxo, de acordo com o sociólogo argeliano Abdelmalek Sayad (1998), “a imigração está diretamente relacionada com o trabalho, e o imigrante "é essencialmente força de trabalho provisória [...], temporária, em trânsito".

Ora, postula-se então além das causas a condição do imigrante enquanto indivíduo que se desloca no espaço, procurando aderir e se adaptar a contextos externos ao seu. Isso posto, o movimento característico da imigração do indivíduo, pauta-se pela saída de sua origem local em busca de trabalho. É nesse sentido que, também se deram as imigrações ao Brasil, e no caso em específico dos italianos ao Brasil, o andar da valorização das culturas europeias para formação de uma identidade nacional avançada.

Nesse envolver, o sociólogo espanhol Manuel Castells (2000, p. 22), entende a identidade como "o processo de construção de significado com base em um atributo cultural ou ainda um conjunto de atributos culturais inter-relacionados, o(s) qual(quais) prevalece $(\mathrm{m})$ sobre outras fontes de significado". E assim, em um esforço de síntese, essa perspectiva segue o pressuposto de que comumente, se vê que essa é uma das questões basilares trazidas quando trata-se da temática da imigração italiana ao Brasil, entendendo os imigrantes como atores sociais provenientes de um espaço cultural praticado.

Nessa mesma toada, ainda segundo Castells (1999, p. 22-23) o conceito de identidade a atores sociais atribui-se como sendo "o processo de construção de significado com base em um atributo cultural, ou ainda, um conjunto de atributos culturais inter-relacionados, o(s) qual(ais) prevalece(m) sobre outras fontes de significado”. Destarte, o poeta, crítico e ensaísta 
inglês Thomas Eliot substancialmente apreende o desejo dos imigrantes em se estabelecer socialmente, mantendo os laços culturais e afetivos comuns, de forma que, mantendo o entendimento de que "[...] a cultura de um indivíduo é dependente da cultura de um grupo ou classe, e que a cultura de um grupo ou classe é dependente da cultura do conjunto da sociedade à qual pertence aquele grupo ou classe" (ELIOT, 2011, p. 23).

Comunga-se da concepção de que um dos pontos centrais da discussão é que em meados da década de 80 do século XIX o Brasil instituiu uma política imigratória, que começou com o objetivo de financiar europeus para que se tornassem pequenos proprietários e produtores de terra, a fim de ocupar e movimentar economicamente as regiões do sul do país, mas que terminou com os grandes proprietários de terra, agricultores da exportação, financiando a vinda destes para usá-los na agricultura (ALVIM, 1998, p. 231). Esses elementos também potencializam o tipo de imigrante agradável aos olhos da elite dominante, outro aspecto a sublinhar é o movimento político que incentivara a vinda dos imigrantes europeus, vistos naquela altura como projeto amplo de desenvolvimento econômico e social.

Nestas circunstâncias, com a abolição da escravatura em 1888 e com a Proclamação da República em 1889, profundas mudanças na estrutura produtiva da sociedade estavam em andamento, visto que, libertados os escravos negros, fora imposto o discurso de que as lavouras, em especial as de café, careciam de mão de obra mais apurada, para assim implantar uma necessidade de imigração para suprir a mão de obra negra. E concomitantemente, indo pelo viés de que a cidade de São Paulo, nesse momento, era um enorme centro de intercâmbio da força de trabalho, partiram-se inúmeras caravanas de imigrantes para o interior rumo as novas fazendas de café do oeste (VANGELISTA, 1991).

Visto ainda que, a consolidação desses fluxos migratórios estavam ligados globalmente, como reforça o historiador e professor João Fabio Bertonha em seu livro intitulado A imigração italiana no Brasil, exalta a informação que no século XX existiam “italianos e seus descendentes em toda a América Latina, nas colônias europeias da África e da Ásia e no Leste Europeu, além de grupos consideráveis no norte da África, especialmente na Tunísia, no Egito, além do continente australiano" (2004, p. 9-10).

Nesse viés, Bertonha(2004) oferece um breve panorama que sobrevoa a migração italiana aos variados continentes, deixando a entender a magnitude que cerca o debate. E assim, com efeito, ao tratar da condição específica do Brasil, em que recebera um grande contingente de imigrantes italianos, a contar desde a abolição da escravatura (1888) e durante 
as primeiras décadas da Primeira República(1889-1930), de modo claro, que a condição econômica propiciara em parte tal condição imigratória. Nesse caminhar, em sentido complementar ao argumento trazido por João Bertonha (2004), o literato Luiz Busatto (1990, p.242) ao refletir acerca da "fuga" do italiano para a América, caminha a englobar a questão dentro da situação caótica vivida na/pela Itália. Assim:

Quem deixa a pátria onde nasceu por causa da pobreza, da fome, das guerras e da miséria coletiva é porque foge do inferno, e procura encontrar o paraíso ou o eldorado noutro lugar. Não é preciso apelar para os relatos míticos e transcendentais da religião que colocam um inferno e um paraíso além. Os italianos viviam uma realidade histórica crucial em que o inferno era a Itália, o paraíso era a América (...) (BUSATTO, 1990, p. 242).

Pelo excerto, se a situação vivida na Itália remetia ao caos social, o continente Americano, e mais especificamente o Brasil, surgia aos italianos como uma chance de novo recomeço. A condição econômica vivida aqui favorecia o imigrante, e por seu turno, o historiador estadunidense Warren Dean expõe que a economia cafeeira criou a infraestrutura necessária para o surgimento da industrialização; o café trouxe a ferrovia, as estradas, o aumento da população e da mão de obra livre com o fomento à imigração; o café trouxe também a prática de comércio exterior, a monetização da economia e o desenvolvimento de um mercado para produtos manufaturados (Dean, 1971, p. 9-16).

Assim, insere-se também nessa estrutura que tais aspectos, aqui delineados, permitem ensejar que na nova moldura do Brasil enquanto país civilizado, a imigração possuidora de uma representação além de um ato político voltado a substituição da mão de obra escrava, também continha um ato ideológico de limpeza das más heranças culturais e sociais deixadas pelos índios e negros. Nessa dinâmica que se imbrica, a consolidação desses novos fatores como a necessidade econômica, promoveu a questão imigrante em uma série de discursos associativos que caminhavam a reforçar simbolicamente a imagem e própria identidade do indivíduo brasileiro, deixando-o mais símile à imagem do europeu ocidental, com características físicas e culturais aproximadas.

Para o historiador estadunidense Michael Hall (1979, p. 202), não há dúvida que as origens da imigração em grande escala estão "intimamente relacionadas à questão da escravidão. Embora frequentemente se diga que a abolição tornou possível a migração em massa, provavelmente a relação oposta está mais próxima da verdade”. Destarte, que o fator econômico favoreceu e serviu de incentivo para a imigração, não resta dúvida, entretanto, ressalta-se que havia implícita nessa movimentação uma questão de cunho mais profundo 
ligado a melhoria da raça e construção da identidade nacional que mais se aproximasse de um espírito europeu.

\subsection{Incentivo à imigração dos povos de "boa" raça e cultura}

Aliando-se a estes fatores, imprescindível, pois, salientar que a questão basilar que estrutura o discurso do "bom imigrante", ou seja, de forma mais nítida referindo-se ao sujeito europeu como aquele indivíduo capaz de responder aos anseios de modernidade e projeto civilizatório requerido pelo discurso político. Partindo dessa premissa, o racismo foi incorporado à visão da política história, transformando-se numa das principais armas do imperialismo e, em muitos países, serviu como ideologia a orientar políticas de Estado (ARENDT, 2004, p. 189; FOUCAULT, 2005, p.199). Não obstante, houve ainda um modelo de racismo cultural que sobrevoou o fim do século XIX ao início do XX no tocante à consideração da práticas indígenas e africanas, sendo elas religiosas, culturais, dialetos, vestimenta, de forma assim como percebe-se, o italiano estaria apto à visão de um Brasil europeizado, branco e portador de práticas culturais valorizadas.

O historiador norte-americano Thomas Elliot Skidmore na obra Preto no branco: raça e nacionalidade no pensamento brasileiro (2012) trabalha justamente a questão imigrante, em capítulo que intitula A imagem nacional e a busca de imigrantes, lembra do anseio das autoridades políticas em "vender" o Brasil no exterior, passando uma imagem de país frutífero a receber de bom grado imigrantes, por ser um país acolhedor, pacífico, rico em terras e belezas naturais, e como exemplo, deu-se o Barão do Rio Branco (1845 - 1912) e sua atuação diplomática na França como ministro das Relações Exteriores entre 1902 e 1912.

Não obstante, conforme é pontuado nesse mesmo diálogo pelo estudioso Thomas Skidmore "os republicanos acreditavam piamente na necessidade de atrair imigrantes para o Brasil. O uso de mão de obra importada da Europa fazia parte de seu compromisso para com o desenvolvimento econômico[...]"(SKIDMORE, 2012, p. 201). Nesse sentido, havia os considerados mais aptos a estarem imigrando ao Brasil, ainda que a raça europeia fosse sinalizada como a mais avançada do mundo, havia aqueles povos que se adaptariam mais fácil e rapidamente, tanto que em texto publicado no jornal Correio Paulistano(1854-1964) em 8 de Julho de 1925, na coluna de Ensaios Economicos e Socieaes, o escritor Lino Garcez em texto intitulado Immigração, expunha que: 
Dá optimo resultado a escolha das immigrações. Todos os povos não são dotados das mesmas qualidades, a capacidade de trabalho por elles desenvolvida, as differenças de raça e de clima são nelles profundamente sensíveis. No Brasil, e principalmente em São Paulo, as immigrações mais vantajosas tem sido a italiana e a portugueza. Muito devemos a esses dois povos. Activos, laboriosos e intelligentes, são dotados para o trabalho, e a grande facillidade de adaptação aos nossos costumes, aos nossos meios de vida, aos nossos climas que é seu traço característico faz que elles vivam tão bem entre nós como si estivessem no seu próprio paiz.[...] Dos 2.000.000 de immigrantes entrados no Brasil a partir de 1827, e dos quaes 1.548.618 se estabeleceram em S. Paulo, a maioria é constituída por italianos e portuguezes, sendo regular o coeficiente de alemães, hespanhoes, turcos, russos e japonezes, e bastante diminuto relativo aos outros paizes.

Não por acaso, o texto acima publicado no Correio Paulistano, um dos mais importantes jornais de circulação da cidade de São Paulo e órgão oficial do Partido Republicano Paulista (PRP) durante a primeira metade do século XX, envolve o debate acerca dos imigrantes mais aptos, que com facilidade se adaptavam ao contexto sociocultural do Brasil. Lino Garcez em sua análise, "elege” os italianos e portugueses como as imigrações mais regulares e frequentes desde 1827. Tenciona ponderar que, talvez pelo clima, pelo idioma ou então pela cultura, povos vindos de Itália e Portugal tendiam a se adaptar mais rapidamente à engrenagem de vida da sociedade brasileira. Sendo considerada ainda aceitável a entrada e imigração de outros povos como alemães, espanhóis, turcos, russos e japoneses. É de se imaginar que as indagações em jogo na mente das elites se voltavam a refletir: Com quais raças se fazia uma boa nação? Era possível construir uma identidade nacional com os povos existentes no Brasil ?.

Nesse fluxo, é imperial e imprescindível trazer à baila o discurso cientificista que atingia o mundo, é assim que o historiador Vanderlei de Souza parte da concepção de que: "No Brasil, as questões raciais sempre constituíram um quadro controvertido[...] especialmente[...] quando as teorias raciais, disciplinas e instituições científicas europeias apontavam inexistente hierarquias entre os diversos grupos humanos"(SOUZA, 2019, p.96).Outrossim, pelas palavras direcionadas por Souza(2019), as formas de convívio são diretamente afetadas pelos ideais científicos no pensamento de raça e identidade que invadiam o contexto de vida no Brasil, especialmente no fim do século XIX. Passar a ser questionados os valores culturais identitários brasileiros, justamente por portarem características indígenas e negras, povos àquela altura tidos como inferiores.

Não obstante, com a consolidação dos estados-nação, ocorrida entre o fim do século XVIII início do século XIX, a construção da identidade nacional passa emergencialmente a ser uma das prioridades no Brasil, tanto por parte da elite econômica como da elite intelectual, que via a necessidade de um sentido próprio de país, reiterando sua força produtiva, em 
prisma social e cultural. Segundo o historiador inglês Eric Hobsbawm (2002) "o nacionalismo vem antes das nações. As nações não formam os Estados e os nacionalismos, mas sim o oposto (p. 19)".

Ao trabalhar a formação dos nacionalismos entre as nações, é na obra $A$ identidade cultural na pós-modernidade que o sociólogo Stuart Hall que torna evidentemente, assim, que o sentido de "culturas nacionais" e mesmo o sentido de "nação" são imaginários (HALL, 1998, p. 48/49), ou seja, assim constando, o pensamento para elaboração de uma identidade cultural com viés europeizado vinculava-se ao projeto político em atrair os indivíduos da Europa, em particular os italianos, com fins a branquear a raça brasileira e incluir novos hábitos que conseguissem apagar marcas culturais deixadas por negros e indígenas, não dignas de um país civilizatório.

Vanderlei de Souza trata em questão semelhante a construção da nacionalidade por meio da busca da identidade nacional, "a partir dos anos 1910, com a emergência de um espírito nacionalista que brotava entre um grupo de importantes intelectuais e cientistas formados na passagem do século XIX para o XX" (SOUZA, 2019, p.52). Com efeito, era preciso trabalhar a imagem do brasileiro enquanto indivíduo mais civilizado, culto, educado e higiênico. Para tanto, pensar em medidas para melhorar o país fazia-se imperial. "O desejo de retirar o Brasil do tão propalado atraso civilizacional [...] possibilitou formular algumas das mais originais e bem ideias sobre o Brasil e a identidade nacional” (Idem, p.53).

Contudo, cabe indagar em que medida as "boas" origens do imigrante favoreciam sua entrada no Brasil como forma de fortalecimento de um projeto político instaurado na Primeira República (1889-1930). É neste contexto que em A centralidade da cultura: notas sobre as revoluções culturais do nosso tempo (1979), Stuart Hall raciocina que todas as ações sociais são culturais, uma vez que "expressam ou comunicam um significado e, neste sentido, são práticas de significação" (HALL, 1997, p. 16).

Dessas assertiva, criam-se modelos de identidades buscadas aos moldes dos desejos das classes dominantes, de modo que a imigração viria a obedecer tais anseios, incrementando sobre o povo brasileiro contornos culturais europeus, tais tidos como a culinária, o idioma, o modo de portar-se, a religião cristã. É nesse prisma que novamente remetemo-nos à obra Renato Kehl e a eugenia no Brasil: ciência, raça e nação no período entreguerras (2019), de Vanderlei de Souza, para tratar do "sonho" da elite em europeizar o Brasil com a vinda dos italianos, unindo o útil ao agradável.

Naquele contexto, Fernando de Magalhães, vice-presidente da Sociedade Eugênica de 
São Paulo, acreditava que o tipo de miscigenação em andamento no Brasil caminhava no sentido benéfico com a vinda dos imigrantes europeus. "Como exemplo de sucesso de miscigenação que ocorria no território nacional, o autor lembrava que a população de São Paulo, antes vista como feia, ‘[...] é hoje bonita após o cruzamento com o italiano' ”(SOUZA, 2019, p.96). Isto implica trazer uma questão tangente ao debate, se a identidade buscada pela intelectualidade e elite brasileira ancorava-se na e pela imigração europeia, criar uma identidade nacional autossuficiente perpassava por reforçar a raça, tornando-a mais bela corporalmente.

Cumpre expor que aos olhos da elites, os brasileiros por portarem e serem formados e formadores de raças inferiores, como indígena e negra, nunca alcançariam uma identidade forte o suficiente. Urge expor que, a discussão envolvendo o processo imigratório no início do Brasil república esteve intimamente relacionada com a questão racial, grande parte da elite apoiada pela intelectualidade brasileira comungava da crença do "bom imigrante", aquele vindo da Europa com capacidade mental e características culturais mais evoluídas se comparada a outros povos. É essa a visão compartilhada pela antropóloga e historiadora Lilia Schwarcz que na obra $O$ espetáculo das raças(1993) expõe que:

Em meio a esse projeto grandioso, que pretendia retirar a diversidade humana do reino incerto da cultura para localizá-la na moradia segura da ciência determinista do século XIX, pouco espaço sobrava para o arbítrio do indivíduo. Da biologia surgiram os grandes modelos e a partir das leis da natureza é que se classificavam as diversidades. Certamente essa não era a única versão que explicava naquele momento, as sociedades em seu comportamento. É possível dizer, no entanto, que os modelos deterministas raciais foram bastante populares [...]. O modelo racial servia para explicar as diferenças e hierarquias, mas feitos certos rearranjos teóricos, não impedia pensar na viabilidade de uma nação mestiça (SCHWARCZ, 1993, p. 325).

Com efeito, mediante o excerto acima, é de se entender que a raça passara a predominar e delimitar os níveis evolucionistas da humanidade, de forma assim então a entender que "todos os defensores da imigração estavam de acordo em um ponto: a absoluta necessidade de recrutamento de mão de obra agrícola europeia. [...]achavam que os europeus eram superiores aos brasileiros nativos" (SKIDMORE, 2012, p. 204). Faz-se mister adicionar que tal condição de superioridade europeia era entendida pelas elites e intelectuais aqui no Brasil em nível macro, em que tanto poderia aplicar atribuir aos europeus uma elevação social, racial, bem como cultural e mental.

Cumpre adicionar ainda que, talvez seja plausível expor e partilhar do entendimento de que as condições sociorraciais presentes no Brasil influíram de forma direta na construção do Estado de São Paulo e sua configuração econômica, cultural e social. Nesse ínterim, núcleos coloniais italianos estabelecidos numa engrenagem de convivência plural com outros 
povos formavam uma mescla étnica, não esquecendo das variáveis de sociabilidade que mantinham os laços dessas comunidades imigrantes em conjunto vivo de suas origens.

\section{Conclusões}

À guisa de conclusão, o texto procurou destacar as correntes de imigração dos italianos que ocorreram em grande escala no pós abolição da escravatura percorrendo toda a primeira metade do século XX, envolvendo para isso, uma abordagem atenta à complexidade conceitual histórica das condições perpassadas naquele momento. Sem dúvida, ao trazer em foco a condição dos imigrantes italianos no interior de São Paulo, encontraram-se questões econômicas e socializadoras que contribuiriam para a imigração italiana, o que por conseguinte, espalhou as formas e laços culturais desses sujeitos.

Como se não fosse o bastante, a discussão primou também por considerar os discursos políticos em torno da imigração, envolvendo o branqueamento da raça brasileira. Insta inferir, ainda, que há muito a ser caminhado neste percurso em torno do estudo da questão da vinda dos imigrantes, e até olhado por um viés interdisciplinar, que congrega a história e as ciências sociais, ao trazer conceitos e autores da antropologia, economia e sociologia para dialogar a respeito das identidades culturais formadas.

\section{Referências}

ALVIM, Zuleika. Imigrantes: a vida privada dos pobres do campo. In: NOVAIS, Fernando A. (org.). História da vida privada no Brasil. São Paulo: Companhia das Letras, 1998.

ARENDT, H. Origem do totalitarismo. São Paulo: Companhia das Letras, 2004.

BERTONHA, J. F. A imigração italiana no Brasil. São Paulo: Saraiva, 2004.

BUSATTO, Luiz. Dilemas do Imigrante Italiano no Espírito Santo. A presença italiana no Brasil. Volume II. Porto Alegre, p.241-259, 1990

CASTELLS, Manuel. O Poder da Identidade. São Paulo: Editora Paz e Terra, 2000.

. A Era da Informação: Economia, Sociedade e Cultura - O poder da Identidade . Vol. 2. São Paulo, Paz e Terra, 1999.

CORREIO PAULISTANO (SP). São Paulo: 1854-1939. Disponível em: http://memoria.bn.br/DocReader/docmulti.aspx ?bib=090972\&pesq=. Acesso em março de 2020.

DEAN, Warren. A industrialização de São Paulo (1880-1945). São Paulo: Difusão Europeia do Livro, 1971

ELIOT, T. S. "Notas para a definição de cultura”. Trad. Wolf, Eduardo. Ed. Realizações, São Paulo, 2011. 
FAUSTO, Boris. Historiografia da Imigração para São Paulo. São Paulo: Editora Sumaré: FAPESP, 1991.

FOUCAULT, M. Em defesa da sociedade. São Paulo: Martins Fontes, 2005.

HALL, Michael. Italianos em São Paulo, 1880-1920. Anais do Museu Paulista. Separata XXX. São Paulo, 1979.

HALL, Stuart. A centralidade da cultura: notas sobre as revoluções culturais do nosso tempo. In: Educação \& Realidade, 22(2): 15-46, jul./dez., 1997.

. A identidade cultural na pós-modernidade, Rio de Janeiro, DP\&A Editora, 1998.

HOBSBAWM, Eric J. Nações e Nacionalismos Desde 1780. $3^{\text {a }}$ Ed. Paz e Terra, Rio de Janeiro, 2002.

LESSER, Jeffrey. A negociação da identidade nacional: imigrantes, minorias e a luta pela etnicidade no Brasil. São Paulo: Editora UNESP, 2001.

MASSEY, Douglas S. The social and economic origins of immigration. In: ANNALS, AAPSS, 510, July 1990, p. 60-72. Disponível http://journals.sagepub.com/doi/abs/10.1177/0002716290510001005. Acesso em: 11 mar. 2020.

OLIVEN, Ruben George. A Antropologia de grupos urbanos. Editora Vozes Ltda, Petrópolis, 1996.

SAYAD, A. S. Imigração ou os paradoxos da alteridade. São Paulo: Edusp, 1998.

SOUZA, Vanderlei S. de. Renato Kehl e a eugenia no Brasil: ciência, raça e nação no período entreguerras. Guarapuava: Editora Unicentro, 2019.

SCHWARCZ, L. M. O espetáculo das raças: cientistas, instituições e questão racial no Brasil (1870-1930). São Paulo: Companhia das Letras, 1993.

SKIDMORE, Thomas E. Preto no branco: raça e nacionalidade no pensamento brasileiro. Rio de Janeiro: Paz e Terra. 2012.

VANGELISTA, Chiara. Os braços da lavoura. Imigrantes e "caipiras" na formação do mercado de trabalho paulista, 1850-1930. São Paulo: Hucitec, 1991. 